\title{
O futebol na construção das representações identitárias nos museus
}

Lúcia Alegrias ${ }^{1}$

\section{Resumo}

Os museus desportivos revelam-se atentos às preocupações sociais contemporâneas e às temáticas relevantes para as sociedades plurais, que pautam a adopção do museu por estratégias inclusivas e novas linguagens museais. Envolvem as comunidades conferindoIhes um sentido de participação nos processos de representação cultural e identitária. Constituindo-se o futebol uma produção cultural de um tempo, de uma agora ou de uma formação social específica, poderemos interrogar-nos qual o posicionamento destes museus no âmbito da Sociomuseologia. Por outras palavras, poderemos começar por nos questionar se o ethos dos museus de futebol incorporam a dimensão social produzida, ou se esta sua dimensão é inerente aos discursos museológicos ai concebidos e evocados. Das Salas de Troféus aos Museus de Futebol atuais evoca-se a reflexão sobre os desafios permanentes à redefinição do

1 Doutoranda em Museologia na Universidade Lusófona de Lisboa, é formada em Antropologia pela Universidade Nova de Lisboa - FCSH com especialização no mestrado de Museologia pela Universidade de Évora. Integrou diferentes projectos de investigação científica sobre Museologia e Património Cultural e trabalha atualmente em direção, gestão e consultoria de projetos e actividades culturais. Destacam-se os projetos de museus desportivos de âmbito nacional e internacional. 
O futebol na construção das representações identitárias...

pensamento museológico e ao conhecimento das suas dinâmicas. 0 nosso projeto de investigação privilegia o permanente diálogo com o tema, problemáticas e hipóteses demarcadas pelos conceitos sociais que sustentam a ação museológica nestes museus, como os conceitos de identidade e memória. Processos que surgem estruturados sobre a construção das representações identitárias no futebol.

Palavras-chave: Identidade; Memória; Sociomuseologia; Museus Desportivos; Futebol

\section{Abstract}

Sports museums are attentive to contemporary social concerns and issues relevant to plural societies, which guide the adoption of the museum by inclusive strategies and new museum languages, in order to involve communities by giving them a sense of participation in the processes of cultural and identity representation. Since football is a cultural production of a time, of from now, or for a specific social formation, we can question the position of these museums within the scope of sociomuseology. In other words, we may begin by questioning whether the ethos of football museums embody the social dimension produced, or whether this dimension is inherent in the museological discourses conceived and evoked. From the Trophy Rooms to the current Football Museums, we reflect on the permanent challenges to the redefinition of museological thought and the knowledge of its dynamics. Our research project privileges the permanent dialogue with the theme, problems and hypotheses demarcated by the social concepts that sustain the museological action in these museums, such as the concepts of identity and memory. Processes that arise structured on the construction of identity representations in the football.

Keywords: Identity; Memory; Sociomuseology; Sports Museums; Football 
"É GOOOOOLO!". Poderíamos assumir que no fim do apito final tudo se resume a isto, a uma bola dentro da baliza, ao golo, à vitória. Porém o futebol é um desporto com especificidades próprias que suplantam o seu carácter meramente desportivo, expressa-se pelas emoções, pela produção de memória e identidades, por toda a sua dimensão humana e social. Partindo desta realidade que se apresentará como o mote da nossa reflexão, iremos tecer algumas linhas de compreensão deste fenómeno social no âmbito da museologia.

A premissa base do presente projeto de investigação visa compreender a que lógicas obedecem os museus de futebol no quadro das construção de representações identitárias, sob a análise dos seus processos museológicos.

Tendo como ponto de partida o estudo dos museus desportivos, em particular de futebol no contexto português, o projeto de investigação ambiciona refletir criticamente sobre a experiência adquirida e procura novos conhecimentos na afirmação da Museologia como área disciplinar aplicada, no seu impacto, na sua função e responsabilidade social e de desenvolvimento. Abordagens que se centram num olhar critico teórico-prático sobre os conceitos de programação museológica e exposição nos museus de futebol, numa perspectiva integrada e multidisciplinar. Na qual serão analisados e debatidos os processos museológicos, as representações sociais nos processos identitários dos clubes e a sua sustentabilidade social nas suas dinâmicas de produção-ação.

Contudo, como será possível racionalizar e sistematizar tanto um fenómeno que é pura paixão, que não se limita à materialização do troféu nem a convenção do jogo? É por muitos 
O futebol na construção das representações identitárias...

entendido quase como uma religião que obedece a práticas tidas como sacralizadas e ritualizadas que se materializam, também elas, dentro e fora das quatro linhas de jogo.

Bourdieu na sua obra Poder do Simbólico (1998) define a noção de campo,

\begin{abstract}
"A noção de campo é, em certo sentido, uma estenografia conceptual de um modo de construção do objeto que vai comandar - ou orientar todas as opções práticas da pesquisa. Ela funciona como um sinal que lembra o que há que fazer, a saber, verificar que o objeto em questão não está isolado de um conjunto de relações que retira o essencial das suas propriedades". (Bourdieu, 1998, p.27)
\end{abstract}

O campo na perspetiva de Bourdieu, interpretado como o nosso campo empírico, na redundância do "nosso campo de jogo", permite-nos olhar para as múltiplas ascensões dos museus de deporto, em particular para o futebol.

Se o futebol se apresenta deste modo como um desporto que reforça o campo das representações identitárias refletidas nos museus dos grandes clubes e outros de âmbito mais alargado, definindo discursos museológicos inerentes a este processo social, teremos de ter em conta outros aspectos que intensificam esta realidade. Os discursos metafóricos, a recorrência de uma construção de uma memória e ideologia de pertença, de uma celebração partilhada e vivida que encerra por excelência a produção e reprodução de quadros de significação em torno das diferentes identidades.

Reconhecendo o futebol como um fenómeno social generalizado à escala mundial, as instituições desportivas têm-se revelado cada vez mais permeáveis à actuação dos processos museológicos. Para tal é necessário analisar e entender no âmbito 
dos museus de futebol como os diversos clubes desportivos tratam de forma particular a sua identidade e quais as repercussões sociais enquanto contributo para uma socialização na perspectiva da participação e inclusão; analisar as motivações e valores (linguagens e discursos) que estão na base do entendimento do futebol na contemporaneidade, por exemplo o respeito pelo outro e diversidade cultural; e entender como são construídas as suas narrativas biográficas e como o museu contribui para o seu entendimento.

\section{Memória e identidade no quadro de significações do futebol}

“O estádio de futebol é um espaço celebrativo que apresenta características rituais, (...) onde a performatividade e o formalismo dos praticantes e simpatizantes são essenciais na identificação de um determinado grupo social, na conservação de um desejo de produzir e dar forma a uma comunidade, de repetir conscientemente o passado, de encontrar sentido na recorrência celebrada". (Streapco, 2009,p.4)

Necessitamos de compreender o futebol como um fenómeno social e cultural historicamente produzido. A partilha de conceitos é aquilo que faz com que todos os indivíduos entendam os mesmos códigos culturais - a pertença a um clube. Ou seja, os adeptos de futebol conseguem compreender todos os símbolos e sinais de um jogo, de uma equipa, da mística do futebol, uma vez que têm em comum determinadas práticas, acontecimentos, memórias, entre outros aspectos. Pelo contrário, quem não fizer parte deste conjunto poderá não compreender as suas referências e quadros de significação.

Uma vez que elementos da mesma cultura partilham conjuntos de conceitos, valores, crenças, práticas e símbolos que 
O futebol na construção das representações identitárias...

Ihes permitem interpretar, de forma semelhante, códigos culturais (Hall, 1997), parece-nos relevante estudar os conceitos de comunidade imaginada de Anderson (1996), ou de Foucault (1998), para o qual a cultura desportiva é estudada através do corpo e o poder, recuperando os conceitos das Ciências Sociais que se têm debruçado pelos estudos da Sociologia do Desporto, do Futebol e da História, relacionando-se diálogos interdisciplinares.

A partilha de conceitos que permite uma interpretação em conjunto de vários signos e códigos culturais, é uma das grandes premissas que permitem ao futebol ser um fenómeno de sucesso. Existem uma linguagem e um comportamento que é perfeitamente compreensível por quem faz parte desta cultura, que simultaneamente os une e os afasta dos outros, pela instigação da diferença, que não partilham esse mesmo código e identidade. Contudo, quando falamos dos adeptos de um clube referimo-nos geralmente a uma multidão difusa, com algumas características de "público". Remete-nos para a noção de uma comunidade, com ideias e objectivos em comum, rivalidades internas e externas, uma hierarquia, com noções, ideais e valores que podem ser considerados comuns e globais. O antropólogo Desmond Morris (1981) fala-nos da conotação de "Tribo do futebol". O sentimento de pertença parece ser experimentado como um sentimento de união, como resultado da partilha das vitórias e derrotas da sua equipa com outros que têm os mesmos interesses desportivos (Branscombe \& Wann, 1991). A construção da identidade de um clube de futebol ocorre ainda na relação com os seus adversários, aqueles que são identificados como o(s) outro(s) e que demarcam pela competitividade e rivalidade no conjunto de tensões, conflitos e "amor-ódio" inerentes. Esta identidade ficará latente quando outros valores com uma outra identidade de nação se sobrepõe à lógica do associativismo.

Outro aspecto fundamental desta construção é o da memória histórica e social do clube, dos seus protagonistas 
(jogadores, dirigentes, adeptos), as suas conquistas ou mesmo derrotas marcantes, e do seu património (material e intangível). Podemos também identificar o conjunto de condutas, traços, cores, valores e práticas (quase que rituais) que surgem associados a estes contextos. A um outro nível podemos incluir "outras formas de preservação da memória como as práticas corporais utilizadas dentro do campo pelos jogadores (dribles, passes, gingas de corpo etc.) e as utilizadas pela torcida (cantos, músicas, gritos, danças etc.)" (Streapco, 2009,p.4).

Os museus de futebol assumem nos seus discursos museológicos o reforço da produção de identidades socioculturais de expressão territorial na qual a avaliação de supremacias com base nos resultados competitivos resultantes dos diferentes campeonatos é imposta, conforme evidencia a análise do Desporto Moderno no qual se inscreve o futebol (Elias e Dunning, 1992).

Identidade e memória são indissociáveis. As construções discursivas decorrentes da atividade inter-relacional entre os sujeitos, e entre os sujeitos e o presente, dão-nos o quadro referência da atuação da memória na ação museal. Assim, recorrendo aos estudos de Halbwachs (1990), Nora (1993), Pollak (1989; 1992), Santos (1998; 2002; 2003), Connerton (2003), podemos assumir que existem duas formas de se reevocar uma memória e que esse processo pode ser elaborado tanto individual quanto coletivamente. No carácter ritualizado do futebol podemos encontrar aproximações ao conceito de 'memória coletiva' de Halbwachs (1950) na importância do papel de determinados quadros sociais - como a família, o grupo profissional ou a classe social - enquanto matriz da memória e de Connerton (1999) que refere que a memória é transmitida através de performances (mais ou menos) rituais por atos de transferência de importância crucial como as cerimónias comemorativas e as práticas sociais, destacando-se as narrativas como também uma característica de toda a memória social. 
O futebol na construção das representações identitárias...

A memória coletiva é fundamental no processo de construção desta identidade ao fornecer os códigos de classificação e interação social que permitem a fixação de representações sociais que dão unidade, sentido de pertença e coesão ao grupo. Manifesta-se a partir da constatação de que todo sujeito compartilha com o grupo ao qual pertence acontecimentos e práticas que se configuram como experiências fundamentais para a constituição do quadro de referências onde os contornos da sua memória se configuram. Este entendimento conduz-nos à evocação das memórias na ação museal no qual o visitante se depara com os objetos, as imagens e as metáforas do discurso expositivo. É neste contexto que o museu de futebol opera com a memória. Os adeptos reconhecem os acontecimentos ainda que por imagens difusas corporizadas a partir das narrativas dos elementos que compõem a memória e que reforçam a identidade dos clubes. Conforme Georges Vigarello refere

\begin{abstract}
"A fascinação gerada pelo esporte, além disso, se relacionava também com $o$ fato do futebol se transformar em uma maneira de contar histórias excepcionais, uma maneira de transfigurar o ideal em tema sempre mais visível e concreto, e ao fato do jogo se transformar em risco ao projeto de poder vigente." (Streapco, 2009,p.3)
\end{abstract}

Os museus enfrentam o tempo e as incontingências do esquecimento, bem como colaboraram para que uma dada comunidade estruture suas ações em torno de referenciais identitários comuns. Estas evidencias são, segundo Pollak (1992):

\footnotetext{
"Acontecimentos dos quais a pessoa nem sempre participou mas que, no imaginário, tomaram tamanho relevo que, no fim das contas, é quase impossível que
} 
ela consiga saber se participou ou não. Se formos mais longe, a esses acontecimentos vêm se juntar todos os eventos que não se situam dentro do espaço-tempo de uma pessoa ou de um grupo. É perfeitamente possível que por meio da socialização política, ou da socialização histórica, ocorra um fenômeno de projeção ou identificação com determinado passado, tão forte que podemos falar numa memória quase que herdada" (Pollak, 1992, p. 201).

Contudo, os acontecimentos, as recordações, as práticas e as imagens não se apresentam à memória como formas acabadas ou perfeitamente delineadas. No momento em que são evocadas, as memórias relacionam-se sempre a outros elementos, elementos que, por sua vez, as tornam diferentes e Ihes configuram novas significações. De acordo com Pierre Nora (1993):

"A memória é a vida, sempre carregada por grupos vivos e, nesse sentido, ela está em permanente evolução, aberta à dialética da lembrança e do esquecimento, inconsciente de suas deformações sucessivas, vulnerável a todos os usos e manipulações, susceptível de longas latências e de repentinas revitalizações. A memória é um fenómeno sempre atual, um elo vivido no eterno presente. Porque é afetiva e mágica, a memória não se acomoda a detalhes que a confortam; ela se alimenta de lembranças vagas, telescópicas, globais ou flutuantes, particulares ou simbólicas, sensíveis a todas as transferências, cenas, censuras ou projeções. A memória instala a lembrança no sagrado. A memória emerge de um grupo que ela une, o que quer dizer que há tantas memórias quantos grupos existem; que ela é 
O futebol na construção das representações identitárias...

por natureza, múltipla e desacelerada, coletiva, plural e individualizada. A memória se enraíza no concreto, no gesto, na imagem, no objeto (NORA, 1993, p. 9).

No processo de novas significações e na construção de discursos identitários os sentidos que atribuímos à memória derivam da negociação e diálogo com o outro dentro dos quadros espaciais onde operam a memória, o esquecimento e a identidade, neste sentido Santos (2002) refere:

\begin{abstract}
“(..) por mais que pareçam fruto de sentimentos e pensamentos exclusivamente individuais, somente existem como parte de estruturas ou contextos sociais. A lembrança do passado, portanto, não é o ato individual de recordar, mas o resultado de laços de solidariedade, e, como tal, só pode existir porque foi constituída em relação a todo um conjunto de noções e convenções comuns, presentes em pessoas, grupos, lugares, datas, palavras e formas de linguagens das quais nós fazemos ou fizemos parte" (SANTOS, 2002, p. 131).
\end{abstract}

\title{
Os museus de futebol sob o olhar da sociomuseologia
}

Numa reflexão da museologia e das questões sociais contemporâneas, o desporto assume-se como uma fenómeno económico, social, cultural e antropológico de enorme relevância no âmbito das vivências humanas, destacando-se o futebol um dos maiores fenómenos de massas do século XXI. Tem sido algo ignorado pelas ciências sociais e humanas que têm negligenciado a importância que o desporto e o futebol possuíram ao longo do século XX para a compreensão da história do Homem 
contemporâneo. Ao estudarmos a forma como as instituições desportivas preservam e interpretam o seu património estamos, fundamentalmente, a entender como o homem desportivo, olha para o seu património, para a sua história, para a sua identidade, enfim, para a sua memória conferindo e restituindo ao desporto a sua dimensão humana.

O contributo efetivo que a Sociomuseologia poderá conferir a esta dimensão coaduna-se com a dimensão simbólica e social do desporto, refletindo sobre o papel do desporto na melhoria da vida humana, reconhecendo e valorizando o património desportivo e cultural, os seus valores, as memórias e o seu papel na formação da identidade cultural das comunidades, ao nível nacional, regional ou local. Importa refletir de que forma é que o património desportivo tem sido objeto de estudo no âmbito das reflexões das Ciências Sociais; analisar a forma como as entidades desportivas tratam o seu património e olham para a sua memória coletiva; quais as preocupações patrimoniais expressas nas políticas de planeamento das instituições desportivas; qual a consciência das entidades desportivas para com o seu património; e quais as abordagens, contextos e processos museológicos.

A Museologia Social veio reforçar a inserção do museu nos movimentos sociais e numa democratização cultural, a exploração dinâmica das suas coleções exige uma verdadeira metamorfose da instituição, no sentido de eleger o museu e as suas práticas como campo de reflexão teórica e epistemológica. O museu surge como agente de mudança social, de regeneração, na perspectiva de "alter-museu" conforme nos introduz Pierre Mayrand.

Marc Maure (1995) define a Museologia Social como uma "Museologia de ação" sustentada por um sistema de valores que tem como princípios de atuação a democratização cultural, os novos paradigmas de pluridisciplinaridade e consciencialização, o museu como um sistema aberto e interativo e num permanente diálogo entre os sujeitos. 
O futebol na construção das representações identitárias...

As narrativas biográficas, no âmbito da investigação-ação são uma estratégia museológica privilegiada para envolver as comunidades, contribuindo para a sua valorização, recuperando as suas memórias, representações, identidades e valores. Contudo, o museu pode ser tempo, espaço, memória e também ele esquecimento.

Por outro lado, a construção de uma narrativa museológica obriga ao planeamento de novas estruturas comunicacionais que permitam oferecer aos públicos do museu a possibilidade de estabelecerem um diálogo interrogativo, através do desencadeamento de aprendizagens cognitivas face ao património e memórias apresentadas pela expografia. De acordo com Mário Chagas (2000) é irrefutável que as exposições museológicas estiveram sempre relacionadas com o poder da memória e a memória do poder. Numa análise da história das exposições museológicas podemos verificar como as ideologias são representadas, apresentadas e comunicadas aos públicos no museu. Esta questão é pertinente para a reflexão e discussão dos processos de comunicação da museologia face às questões sociais contemporâneas e, por outro lado, quando o poder das influências da museologia pelas suas narrativas é exercido, maioritariamente, por meio das exposições. Mais uma vez, reconhecemos a pertinência da investigação-ação para a Museologia num contributo efetivo da participação das comunidades na evocação das suas representações identitárias, conscientes que toda a narrativa museológica é construída e não desprovida de poder.

Na sua diversidade de práticas museais, a Sociomuseologia permite e projeta a função principal do museu para as atividades que estão relacionadas com o desenvolvimento social e cultural, onde o museu se assume como instrumento essencial, à disposição da comunidade para, de modo geral, contribuir para uma sociedade com valores de cidadania e mais próxima das pessoas. Introduz no 
processo museológico o princípio da participação na construção das narrativas e da sua relevância social.

De acordo com Judite Primo

"O novo museu, nas suas diferentes formas e tipologias, ao trabalhar com o social pretende responder aos deliceramentos da vida cultural e social. O social é então totalmente reinvestido na vida das comunidades, tornando-se objeto das ações culturais" (Primo, 2014, p.9).

O novo museu é entendido como um espaço que forneça subsídios para a transformação de ideias, de indivíduos e conceitos da sociedade. Como instituição que funcione para o diálogo intercultural, como espaço de democratização de conhecimentos, mobilização social, como "agentes portadores da memória", conforme nos introduz a "Declaração MINOM Rio 2013". Abrem-se deste modo novas perspectivas para a comunicação e atuação museológica.

Neste sentido, Mário Moutinho refere o conceito de 'museu complexo', dotado de novas dinâmicas e conceitos sociais que sustentam a ação museológica no qual podemos enquadrar o nosso projeto de investigação:

"O Museu de Foucault que se constituía como heterotopia pela sua singularidade da acumulação e da intemporalidade, de certa forma deixou de existir, pois tanto uma coisa como outra deixaram de ser centrais para revelarem o museu como instâncias ou processos, de uma polifonia social onde a justaposição das coisas 
O futebol na construção das representações identitárias...

e dos tempos, cede lugar á justaposição das relações de poder e de submissão, da anulação e afirmação das contradições, e da negação ou não da interculturalidade.

O desafio da Sociomuseologia é certamente o de contribuir também para a compreensão desta nova realidade museológica, assente na existência de museus que se afirmam pela utilização simultânea de diferentes conceitos, tornando-se assim numa nova categoria que poderíamos denominar de Museus Complexos. Complexos não pela complexidade do funcionamento das instituições museológicas, mas complexos pela complexidades dos conceitos que sustentam as suas diversas atividades."(Moutinho, 2014, p. 9)

O autor revela-nos que caminhamos para uma nova tipologia de museus que denomina de "Museus Complexos", que combinam na sua ação a utilização diferentes conceitos que sustentam as suas diversas atividades. Nesta reflexão podemos encontrar traços que nos aproximam ao entendimento dos novos museus desportivos de futebol. Os museus de futebol são entendidos como campos da espetacularização, que combinam diferentes linguagens museológicas e expográficas, com recurso às mais avançadas tecnologias ao serviço da prática museal, em combinação com a expografia clássica e elementos cenográficos que nos permitem construir a narrativa museológica e interpretar os diferentes conceitos inerentes. Mais do que espectáculo caminhamos para o consumo da experiência enquanto modelo expográfico privilegiado pelos novos museus e debates dos seus agentes culturais.

É neste sentido que importa perceber o que se altera e 
permanece nos museus desportivos. Reconhecendo que a existência de salas de troféus denota um interesse pela valorização do património cultural dos clubes e associações desportivas a que lógicas obedecem, dentro quadro das suas políticas institucionais, estes novos museus? Contudo, no universo do futebol caracterizado pela sua natureza global, a noção de mercado desportivo global, cria todas as condições para que os clubes de futebol sejam, também eles, marcas. $O$ salto qualitativo da noção de clube desportivo para a de marca internacional encontra-se sustentada nos sucessos desportivos que um clube logra atingir. Vários clubes têm vindo a adotar esta forma de trabalho e de imagem, criando museus que façam corresponder a grandeza das conquistas realizadas com as expectativas dos adeptos e dos seus associados, capitalizando economicamente $\mathrm{o}$ seu percurso histórico. Deste modo, é premente explorar as evidencias dos novos modelos da valorização e reconhecimento da dimensão simbólica, social e humana dos seus patrimónios.

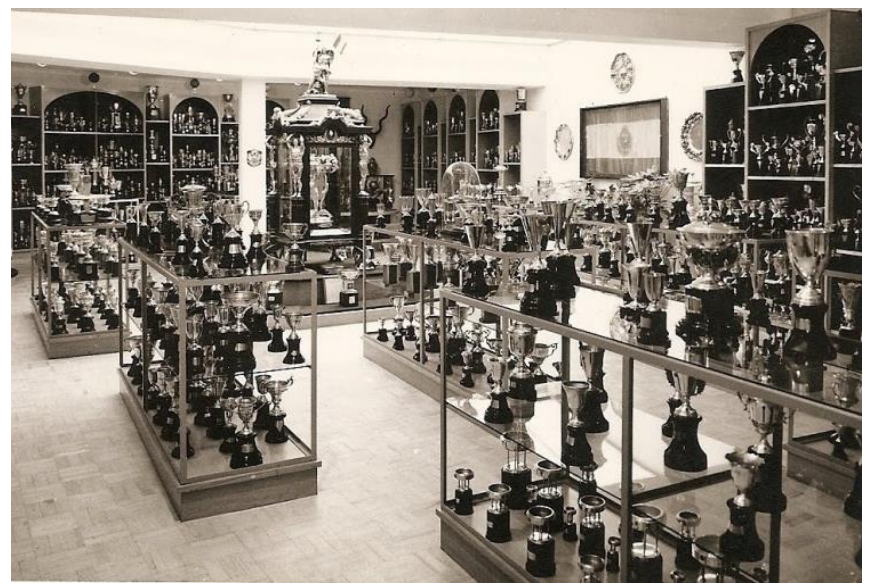

Sala Museu Afonso Pinto de Magalhães nos anos 70. Instalada na antiga Sede do Futebol Clube do Porto da Avenida dos Aliados. Fonte: Arquivo do Museu do Futebol Clube do Porto. 
O futebol na construção das representações identitárias...

\section{O estudo de caso do Museu Futebol Clube do Porto by Bmg}

Inaugurado a 28 de Setembro de 2013, dia do 120. aniversário do clube, o Museu convida-nos a percorrer não apenas a história, mas a conhecer também a mística do Futebol Clube do Porto. Essa mística que se assume vencedora resultado dos valores que o clube identifica como a ambição, a competência, o rigor e a paixão. Tanto adeptos com amantes das modalidades experimentam todo o universo do clube nos diferentes núcleos museográficos.

O Museu do Futebol Clube do Porto é uma experiência única, um lugar de partilha de memória, conhecimento e paixão, um espaço grandioso do ponto de vista cultural que une sócios, adeptos e amantes do futebol num projeto de cidadania e desporto que vai muito além do clubismo. A constelação de estrelas é a conceito narrativo da exposição do museu.

Nomeado para Melhor Museu Europeu do Ano - European Museum of the Year Award (EMYA), 2016, e com o Prémio Inovação e Criatividade da Associação Portuguesa de Museologia (APOM), 2015, o espaço âncora do Museu FC Porto possui uma área total de $7.000 \mathrm{~m}^{2}$ - dos quais $4.000 \mathrm{~m}^{2}$ expositivos, dividida por 27 áreas temáticas. Desde a sua abertura, em 2013, o museu já recebeu mais de 410 mil pessoas, tendo no ano passado a percentagem de turistas estrangeiros sido de $40 \%$.

O museu adopta uma linguagem de inovação quanto ao tratamento museológico, pela sua linguagem expositiva e recursos tecnológicos. Exemplo de museus que introduzem na museologia a reflexão sobre a necessidade ou não de um museu ser integrado por acervo original, ou expressar-se exclusivamente em linguagem mediática que subverte a lógica tradicional dos museus. Este museu apresenta-nos um discurso amplo da paixão do futebol com 
diferentes enquadramentos de representações identitárias do futebol vinculadas à história clubística e da sua memória.

Com soluções artísticas, plásticas e tecnológicas completamente originais e inovadoras, os núcleos museográficos estão articulados com espaços de transição que estabelecem uma interligação com as zonas específicas alusivas a cada temática. No centro da experiência, existe um núcleo - praça central que alberga as peças-âncora do museu - cerca de uma centena dos mais importantes troféus a nível do futebol nacional e as sete grandes taças internacionais que o clube venceu em outras tantas cidades mundiais.

Podemos destacar as seguintes área temáticas onde se caracteriza a dimensão social e identitária do clube na sua relação com o património histórico do clube:

Área "Identidade" - espaço expositivo que celebra a identidade do clube. Na definição das cores azul e branco, a evolução do símbolo emblema do clube, o dragão, os valores, o hino, o protagonismo do território (cidade e região).

Área "Brilho Universal" - este espaço desdobra-se nos pontos de atração do "coração" do Museu. À esquerda surge um espaço sóbrio, em que se apresenta a Galeria de Presidentes; ao centro um amplo espaço dinâmico em que a atenção se divide entre as enormes imagens das grandes vitórias internacionais e a intimidade sugerida pela "Constelação de Troféus" dedicada às conquistas nacionais; à direita a área temática "Nós" dedicado aos sócios. Uma estrela projetada no solo num novo pontocharneira assinala o momento em que o visitante, sempre o centro das atenções poderá decidir por onde ir. 
O futebol na construção das representações identitárias...

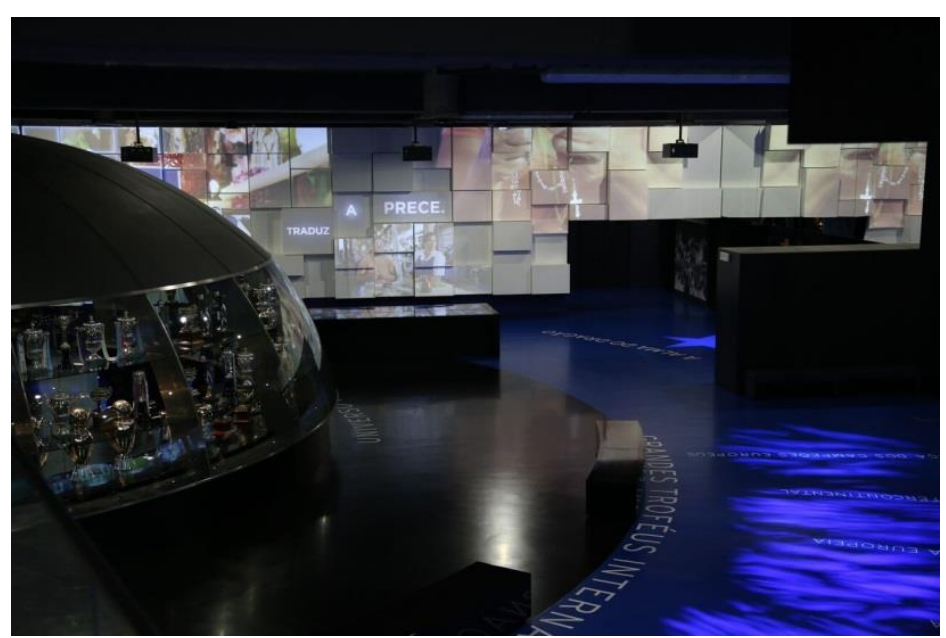

Museu FC Porto by Bmg. Coração do Museu. 2014

Na Área "Nós" (Sócios) - surge uma galeria de fotografias de sócios de todos os tempos e idades. Podemos observar um vídeo no qual os adeptos foram convocados a revelar as suas memórias e vivências sobre o clube e como eles caracterizam o sentido de pertença desta representação identitária. Ainda neste espaço destaca-se o objeto central, a Taça Arsenal comemorativa da extraordinária vitória sobre o campeão inglês em 1948. A expressão da vitória sensibilizou tal forma os adeptos que formaram uma comissão de seis associados para angariação de fundos de subscrição pública em Portugal, Províncias Ultramarinas e no Brasil reunindo o valor necessário para conceber o magnífico troféu.

A Área "Constelação do Dragão" - a dimensão cósmica de um globo de troféus nacionais. Peça nuclear de toda a vivência, este é uma espécie de momento sacro, ativado pela presença dos visitantes, que ali tomam contacto com os troféus de uma forma que Ihes dá dimensão universal. No interior, um firmamento de pontos brilhantes ostenta dinamicamente constelações reconhecíveis, em destaque a constelação do Dragão (Alpha 
Draconis). Do interior, através da transparência do vidro, vislumbrase o movimento em volta.

Nesta praça semi-circular, o visitante depara-se com um pico da narrativa audiovisual que transforma o espaço num todo. Sobre as sete taças internacionais, o vídeowall relata jornadas épicas, ao mesmo tempo que um impressivo vídeo-mapping, na parede oposta, é dedicado à mística do Clube que celebra essas vitórias. A área "Mística Azul e Branca" (vídeo-mapping) apresentanos um vídeo documental sobre a vivência dos adeptos na sua relação com o futebol e o clube. A narrativa é acompanhada pelas palavras do poema épico "Alleluia" de Pedro Homem de Melo alusivas à alma portista. São exploradas diferentes narrativas destacando-se a força das claques, a fé, as superstições, as práticas sociais ritualizadas para assistir-se ao jogo de futebol, a presença do clube no quotidiano, entre outros aspectos.

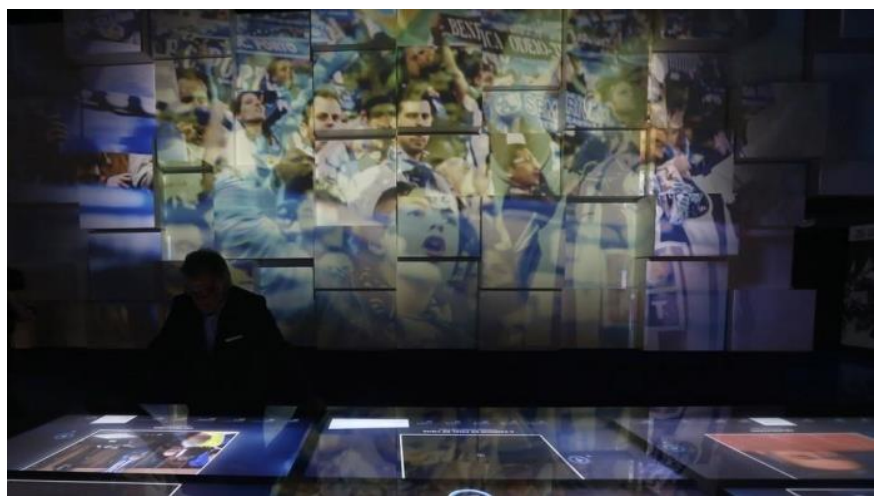

Museu FC Porto by Bmg. Vídeo-documental alusivo aos adeptos do Futebol Clube do Porto. 2014

Estas abordagens híbridas do ponto de vista conceptual e museográfico remete-nos para a análise dos "museus complexos" de Mário Moutinho. A complexidade é tida pelas meta-linguagens que encerra em si mesmo. Por outro lado, a aprendizagem do 
O futebol na construção das representações identitárias...

museu é marcada por "performatividade", ou seja pela sua capacidade de maximizar a eficiência e a eficácia do desempenho em relação às actividades experienciais que enfrenta na sua complexidade. A aprendizagem prevê uma abordagem "participativa", em envolver os corpos, as mentes e as emoções nos vários processos de construção de significado, que ocorrem quase sem vontade consciente (Hooper-Greenhill 2007, p. 37), pressupostos que devem ser considerados no projecto museográfico e expografia. Nos estudos museológicos, por exemplo E. Hooper-Greenhill (1987, 1994, 1996 e 2005), R. Jackson - K. Hann (1994), G. Hein (1998), L. Dierking (2002) e E. Sotto (2007), a atividade multiforme de estimulação sensorial que é acionada e exercida pela interação com as exposições também acrescentam, enriquecem e melhoram, além da aprendizagem, a curiosidade, o interesse, a motivação e as experiências e as dinâmicas exploratórias do próprio público. Podemos ir mais além e verificar que o planeamento de uma exposição poderá ser considerado como um elemento de apoio às teorias mais específicas e detalhadas sobre o "museu de ensino- aprendizagem", com vista à construção de um modelo de análise do mesmo processo de aprendizagem.

Perguntas tais como "para quem", "como", "de que forma" e "quando", foram prementes para o trabalho da exposição do museu FC Porto que se revela agora de sucesso. Importa analisar como os planos de exposição vêm reflectidas as problemáticas da Museologia social e quais os procedimentos e recursos expositivos de forma a comunicar e facilitar as experiências significativas para os visitantes. B. Lord (2007), enfatiza o valor global das colecções, argumentando que: "Museum learning is a transformative experience in which we develop new attitudes, interests, appreciation, beliefs, or values in an informal, voluntary context focused on museum objects" (B. Lord, 2007, p. 19). 
O museu como importante meio de comunicação, tem acompanhado o desenvolvimento comunicacional e tecnológico, no sentido de satisfazer as novas correntes da museologia que se estão a debruçar sobre o papel do museu na sociedade atual. Paulatinamente, com a mudança de percepção do pensamento museológico passamos de uma museologia tradicional centrado no objecto, para uma museologia que introduz novas possibilidades comunicacionais, por sua vez expositivas. Verifica-se novas formas de comunicação estabelecidas através das novas tecnologias, na sociedade da informação. Os museus são compreendidos como instituições em constante transformação. Através dos mais variados recursos e técnicas expográficas, designadamente interatividade digital e virtual nos museus, podem auxiliar na produção de conteúdos e interfaces que possam responder a distintas necessidades e pluralidade de sentidos, quer na interpretação das exposições, quer na participação dos visitantes.

Neste sentido, Mário Moutinho defende que "não foi a Museologia tradicional que evoluiu para uma Nova Museologia mas sim a transformação da sociedade que levou à mudança dos parâmetros da Museologia" (1989, p.102). Como uma nova forma de entender o espaço museal.

A Reunião Intergovernamental da UNESCO, de 2015, que aprova Projeto de Recomendação relativa à Promoção e Proteção dos Museus e das Coleções, incorpora pela primeira vez a necessidade dos museus e coleções terem em atenção a sua função social. Acentua nomeadamente o papel dos museus nas sociedades atuais como espaço de encontro, instrumento de promoção da inclusão social. Enfatiza também o papel da tecnologia e computação nos museus:

"Museums and Information and Communication Technologies (ICTs): 19. The changes brought about by the rise of 
O futebol na construção das representações identitárias...

information and communication technologies (ICTs) offer opportunities for museums in terms of the preservation, study, creation and transmission of heritage and related knowledge. Member States should support museums to share and disseminate knowledge and ensure that museums have the means to have access to these technologies when they are judged necessary to improve their primary functions." (UNESCO, Recomendação relativa à Promoção e Proteção dos Museus e das Coleções, 2015)

De acordo com Cristina Bruno os "Museus, nas últimas décadas têm desempenhado um papel relevante e específico no campo da democratização da cultura, rompendo as barreiras dos seus espaços tradicionais, procurando novos públicos e criando exposições que incorporam linguagens mistas" (Bruno, 1997).

Um museu que apresenta um sistema aberto, interativo e multidisciplinar. A relação entre a Museologia e as tecnologias resulta no desenvolvimento de novas linguagens comunicacionais utilizadas pelos museus. A produção e desenvolvimento das exposições, deverá ter em consideração um processo de design iterativo e participativo que incorpore estes novos elementos expositivos, de forma a permitir aceder a essa pluralidade de interpretações sobre os objetos e temáticas expositivas.

\section{Do conteúdo à ação museal: o reconhecimento patrimonial}

No decorrer do projeto do Museu Futebol Clube do Porto foram criadas algumas ações que integraram as comunidades vinculadas ao clube, nomeadamente com a participação dos sócios e adeptos do clube. A principal ação a destacar decorreu entre 
Março a Setembro de 2013, intitulada como " Campanha "Valor FC Porto", através da comunicação nas redes sociais Facebook e media. No âmbito das comemorações do 120ㅇaㄹiversário do FC Porto, pretendeu-se assinalar esta importante data com diferentes iniciativas desportivas e socioculturais que incidiram no estudo e documentação da história do clube com a colaboração de todos aqueles que para ela contribuíram. A campanha "Valor FC Porto" de doação de coleções teve como objectivo o enriquecimento do acervo do Museu FC Porto, bem como a promoção da preservação e difusão do conhecimento sobre a história, património e memória do clube. Caracterizado como um projeto aberto e dinâmico, de carácter sistemático e permanente, possibilitou a inscrição de novos conteúdos histórico-documentais através do incentivo quer à doação quer ao empréstimo de objetos relacionados com o acervo existente, procurando deste modo suprir lacunas ou torná-lo mais rico e contextualizado. Esta comunicação foi realizada mediante a identificação de potenciais doadores e personalidades importantes para a contextualização da história do clube. Por outro lado esta iniciativa de inventário participativo incentivou à recolha de histórias de vida, à partilha de memória, ao reconhecimento dos seus patrimónios (material e intangível) e ao envolvimento das comunidades no projeto de desenvolvimento do museu.

Numa perspectiva mais teórica Hopper-Greenhill (1998) salienta que algumas investigações museológicas têm vindo a atestar o papel que os museus desempenham na representação social. Os impactos destas iniciativas e o reconhecimento das comunidades e suas representações deverão ser avaliados tal como refere Marília Xavier Cury

“a aproximação das áreas de comunicação e recepção para possibilitar o posicionamento do cotidiano do público e suas interpretações e significações junto ao universo patrimonial das coisas musealizadas. Também, entender como as mensagens museológicas 
O futebol na construção das representações identitárias...

são apropriadas, reelaboradas e inseridas no cotidiano do público visitante, ou seja, como as mensagens museológicas são veiculadas na vida das pessoas e qual o impacto sociológico dessa veiculação." (Cury, 2010, p.277)

A participação e a deliberação dos agentes patrimoniais reforça a primazia do papel das próprias comunidades no reconhecimento e legitimização dos seus patrimónios. 0 empowerment e a participação das comunidades conduz-nos à reflexão sobre os processos de objetificação cultural (Handler 1988) , identificação da comunidade (Bauman, 2003) e a adopção de novos significados culturais, numa perspectiva de património enquanto processo "metacultural" (Kirshenblatt-Gimblett, 2004). Autores como Barbara Kirshenblatt- Gimblett (2004) e Kurin (2004) defendem que qualquer intervenção sobre o património modifica a relação das comunidades com esse mesmo património, a forma como concebem a cultura e a si mesmos, bem como as condições básicas de produção e reprodução cultural, evidenciando de igual modo que a mobilização à participação das comunidades no reconhecimento do seu património pode manifestar uma nova reestruturação desses mesmos grupos.

Importa refletir de que forma o museu é interpretado e representado pelas próprias comunidades, elas sim estruturantes da sua própria ação. Aqui se coloca um dos principais desafios da atuação museológica, decorrente não só das significações simbólicas e interpretativas dos seus acervos, suscitadas no contexto museal, que constituem o seu património material inequivocamente relacionado com a memória social e pelo património intangível, como também de novas abordagens heurísticas atribuídas aos museus no estudo, promoção e divulgação do património. 


\section{Ainda antes do apito final}

O Futebol ao alcançar o carácter universal que hoje o caracteriza, estabeleceu o espaço privilegiado da catarse das paixões, interesses, motivações e tendências de milhões de pessoas, constituindo-se como fenómeno sociocultural de relevante importância. Ao assumir um papel fundamental no espectro sociocultural configura-se também ele como um agente promotor da educação, na partilha de valores e conhecimento que se relacionam com a transversalidade das suas múltiplas evocações e temas. Aos objetos-troféus que evocam as gloriosas conquistas dos clubes e que caracterizam numa primeira instância a essência dos clubes do futebol, surgem associados outros objetos (tangíveis e intangíveis) de igual importância que caracterizam a história dos seus protagonistas e, por outro lado, conferem a mística do futebol evocada na dimensão humana e social - os adeptos.

A dimensão social e identitária de um museu de futebol "clubístico", permite explorar ainda a relação deste museu na representação social que é apropriada por si face à extensão do(s) seu(s) território(s), sendo que há uma dialéctica especifica com o território onde se inscreve. $O$ desenvolvimento de ações educativas com a comunidade é fundamental, refletindo as abordagens desenvolvidas no âmbito da sua programação cultural e no papel efetivo na comunicação e educação dos valores do desporto, identidade e memória.

O contributo da Sociomuseologia que atende ao social como objeto da Museologia (Primo, 2013), impulsionado como já observado por circunstâncias técnicas e museográficas e por uma evolução de abertura da mentalidade e conhecimentos dos museólogos que extravasaram claramente os limites da instituição museal nos moldes da Museologia tradicional. A reflexão produzida veio trazer ao campo museológico novas preocupações, bem como redefinir o lugar que o museu ocupa na sociedade, aceitando a coexistência, num mesmo contexto, de formas culturais de 
O futebol na construção das representações identitárias...

expressões locais, nacionais e globais. Este entendimento veio implicar a investigação de uma nova linguagem museal, de novos paradigmas de investigação e de comunicação do museu.

A construção e aprendizagem de uma nova perspectiva acerca dos museus enquanto espaços vivos, da sociomuseologia, da linguagem museológica, do contacto direto com a comunidade e da importância fundamental do serviço que lhes é prestado, sendo uma relação profícua em termos de aprendizagens contínuas e dialécticas. O principal contributo que a Sociomuseologia confere ao papel do museólogo é o seu olhar sobre o museu, na ampliação da sua atuação e na sua permeabilidade ao objeto social. No caso dos museus desportivos um olhar sobre estes novos museus que se transformam numa outra forma de culto ao futebol.

\section{Bibliografia}

Anderson, Benedict. (1989). Comunidades imaginadas. São Paulo: Ática Antunes.

Bourdieu, Pierre. (1989). O poder do simbólico, Lisboa: Difel Chagas, Mário (2009). A Imaginação Museal: Museu, Memória e Poder em Gustavo Barroso, Gilberto Freyre e Darcy Ribeiro, Rio de Janeiro, Ministério da Cultura/IBRAM

Connerton, P. (1999). Como as sociedades recordam. Oeiras: Celta Editora

Cury, Marília X. (2010) Novas Perspectivas para a comunicação museológica e os desafios da pesquisa na recepção em museus. In: Actas do lo Seminário de Investigação em Museologia dos Países de Língua Portuguesa e Espanhola. Vol. 1, No 1. Porto: Universidade do Porto.

ELIAS, Norbert e DUNNING, Eric. 1992. A Busca da Excitação. Lisboa: Difel. 
Falk John H.; Dierking, Lynn D. (2004). The Contextual Model of Learning. Reinventing the Museum Historical and Contemporary Perspectives on the Paradigm Shift. Oxford: Altamira Press. p. 139142.

Halbwachs, Maurice. (2004). A memória coletiva. São Paulo: Centauro Editora.

Hooper-Greenhill, Eilean. (1998). Los Museos y sus Visitantes. Gijón: Ediciones Trea.

Hooper-Greenhill, Eilean. (2007). Museums and education. Purpose, pedagogy, performance, London and New York: Routledge,

J.H. Falk e L. D. Dierking, (1992). The museum experience, Washington, Whalebasck Books.

Kirshenblatt-Gimblett, B., (2004), "Intangible Heritage as Metacultural Production", Museum International 56 (1-2), 52-65.

Leite, Pedro Pereira; Chagas, Mário; Moutinho, Mário ; Primo, Judite ; Stornino, Claudia (2016), "A Nova Recomendação da UNESCO sobre Museus Colecções sua Diversidade e Função Social", Informal Museology Studies, 1, 13, 19-51.

Leite, Pedro Pereira; Primo, Judite dos Santos (2015), Olhares biográficos em museologia: os desafios da intersubjetividade. In Cadernos de Sociomuseologia, 1, 5, 129-1244.

Lord, Barry, Lord, Gail Dexter Lord. (1998). Manual de gestión de museos, Ariel Patrimonio Histórico

Moutinho, Mário. (1994). A construção do objecto museológico. In Cadernos de Sociomuseologia no4, Centro de Estudos de Sociomuseologia, Lisboa: Universidade Lusófona de Humanidades e Tecnologias.

Moutinho, Mário. (2014). Definição evolutiva de Sociomuseologia: proposta de reflexão. In Museologia Social. Cadernos do Ceom. Ano 27, no 41. Chapecó: Unochapecó, 423-427

Moutinho, Mário. (2015). Entre os museus de Foucault e os museus complexos (no prelo) Moutinho, Mário.(1989). Museus e Sociedade, 
O futebol na construção das representações identitárias...

Cadernos de Património.

Nora, P. (1993). Entre memória e história: a problemática dos lugares. Proj. História, São Paulo, v.10, p.7-28.

Pollak, M. (1992). Memória e identidade social. Estudos históricos, Rio de Janeiro, v. 5, n. 10, pp. 200-212

Primo, Judite. (1999). O Sonho do Museólogo. A exposição: Desafio para uma linguagem museográfica. In Cadernos de Sociomuseologia no 16, Lisboa: Universidade Lusófona de Humanidades e Tecnologia.

Primo, Judite. (2014). O social como objecto da museologia. In Cadernos de Sociomuseologia, n.047. Lisboa: Universidade Lusófona de Humanidades e Tecnologia.

Santos, Maria Célia (2001), Um compromisso social com a museologia. In. Cadernos do CEOM - Ano 27, no 41.

Santos, Myrian S. (2002) . O pesadelo da amnésia coletiva: um estudo sobre os conceitos de memória, tradição e traços do passado. In. Cadernos de sociomuseologia, UHLT, n.19, p.121-150.

Streapco, João Paulo França (2009), Representações e memória social através do futebol em São Paulo, ANPUH - XXV Simpósio Nacional de História - Fortaleza 